\title{
Acute effects of ingestion of black tea on postprandial platelet aggregation in human subjects
}

\author{
Jonathan M. Hodgson*, Ian B. Puddey, Valerie Burke, Lawrence J. Beilin, \\ Trevor A. Mori and Shin-Yee Chan \\ University of Western Australia Department of Medicine and HeartSearch, \\ Royal Perth Hospital, Perth, Western Australia, Australia \\ (Received 29 May 2001 - Revised 11 September 2001 - Accepted 16 October 2001)
}

\begin{abstract}
Results of population studies suggest that black tea can reduce cardiovascular risk. Effects of black-tea polyphenols to reduce platelet aggregability may help to explain any benefits. Given that black tea is often consumed with and after meals, and man spends much of his life in the postprandial state, the objective of the present study was to investigate the acute effects of ingestion of black tea on postprandial platelet aggregation ex vivo. Twenty healthy participants had platelet aggregation and blood lipids assessed before and $4 \mathrm{~h}$ after the ingestion of $50 \mathrm{~g}$ dairy fat on two occasions in random order, corresponding to black tea or hot water. Black tea or hot water (one cup) was consumed immediately following the dairy fat, then after 1.5 and $3.0 \mathrm{~h}$. Platelet aggregation ex vivo was assessed in platelet-rich plasma in response to three concentrations of collagen $(0 \cdot 2,0 \cdot 6,2 \cdot 0 \mu \mathrm{g} / \mathrm{ml})$ and ADP $(2,4,8 \mu \mathrm{M})$. Urinary concentrations of 4- $O$-methylgallic acid were used as an indicator that tea polyphenols were absorbed. Serum total cholesterol and triacylglycerol concentrations increased significantly $4 \mathrm{~h}$ after ingesting the dairy fat, but there was no significant difference between black tea and hot-water treatments on the cholesterol or triacylglycerol responses. Urinary 4- $O$-methylgallic acid concentrations were significantly increased following ingestion of black tea $(P=0 \cdot 0001)$ but not water. Black tea in comparison to hot water did not inhibit collagen or ADP-induced postprandial platelet aggregation. The results of this study do not support the suggestion that reduced postprandial platelet aggregability contributes to any benefits of black tea on cardiovascular risk.
\end{abstract}

Platelet aggregation: Platelet function: Black tea: Polyphenols: Postprandial

Results of population studies suggest that a higher intake of black tea may reduce cardiovascular disease risk (Hertog et al. 1993; Keli et al. 1996). One suggested mechanism is that black tea reduces platelet aggregability (Hertog \& Hollman, 1996), which could lead to reduced risk of thrombosis and cardiovascular events.

Thrombosis, which involves aggregation of platelets at the site of endothelial injury, may lead to accelerated atherogenesis or acute coronary thrombosis after atherosclerotic plaque rupture. The assessment of platelet aggregation in vitro is the most widely used functional measure of platelet reactivity and thrombotic tendency, and may provide an indication of platelet activation. Black-tea polyphenols inhibit platelet aggregation in vitro (Formica \& Regelson, 1995; Pace-Asciak et al. 1995; Janssen et al. 1998; Kang et al. 1999; Neiva et al. 1999), but controlled dietary intervention studies in human subjects with polyphenols found in black tea have so far failed to find any benefits (Conquer et al. 1998; Janssen et al. 1998). In addition, we (Hodgson et al. 2001) and others (Duffy et al. 2001) have recently shown that regular ingestion of black tea for a period of 4 weeks does not alter platelet aggregation ex vivo in fasting plasma. Furthermore, Duffy et al. (2001) showed that acute ingestion of black tea did not alter platelet aggregation in fasting plasma.

The aim of the present study was to investigate the acute effects of ingestion of black tea on postprandial platelet aggregation. Postprandial lipaemia is recognized as a procoagulant state (Mutanen \& Freese, 2001), and any reduction in postprandial platelet aggregation could suggest reduced risk of thrombosis. Previous intervention studies that have examined the effects of polyphenol supplements (Conquer et al. 1998; Janssen et al. 1998) or drinking black

\footnotetext{
Abbreviation: PRP, platelet-rich plasma.

* Corresponding author: Dr Jonathan Hodgson, fax + 6189224 0246, email jonathan@cyllene.uwa.edu.au
} 
tea (Duffy et al. 2001; Hodgson et al. 2001) on platelet function have assessed platelet aggregation in the fasting state. Given that black tea is often consumed either with or after a meal, and that man spends much of his life in the postprandial state, the potential effects of black tea on postprandial platelet function may be relevant. Therefore, we have now assessed the acute effects of ingestion of black tea on postprandial platelet aggregation ex vivo in a controlled crossover trial involving healthy men and women.

\section{Methods \\ Subjects}

Platelet aggregation was assessed in twenty participants, fifteen men and five women (mean age 58.3 (SE 1.5) years), who were recruited from the general population using media advertisements. Exclusion criteria for this study were: women who were premenopausal or postmenopausal and taking hormone replacement therapy; a usual alcohol intake exceeding $40 \mathrm{~g} / \mathrm{d}$; current or recent ( $<6$ months) smoking; any history of heart, liver, renal or gastrointestinal disease or disorder or diabetes; use of any medication including aspirin or non-steroidal anti-inflammatory drugs. The Royal Perth Hospital Ethics Committee approved the project, and all participants gave written informed consent.

\section{Experimental design}

The acute effects of black tea, compared with hot water, on postprandial platelet aggregation were assessed following a $12 \mathrm{~h}$ overnight fast. Two clinic visits, corresponding to black tea or hot water, were conducted 1 week apart on the same day of the week, at the same time of day, and in random order. Ten participants had hot water at the first visit and black tea at the second visit, and ten participants had black tea at the first visit and hot water at the second visit. At each visit a blood sample was taken for measurement of baseline platelet aggregation and blood lipids and a spot urine sample was taken for measurement of markers of tea polyphenol intake. Participants then drank $125 \mathrm{ml}$ dairy cream containing $50 \mathrm{~g}$ fat (400 $\mathrm{g}$ fat/l). Black tea or hot water (one cup) was consumed immediately following the dairy fat and again at 1.5 and $3.0 \mathrm{~h}$ after the cream drink. Drinking tea at regular intervals throughout the postprandial period ensured that plasma concentrations of polyphenols remained elevated, and that the assessment of platelet aggregation coincided with elevated plasma concentrations. Peak plasma concentrations of tea-derived polyphenols occur at about $2 \mathrm{~h}$ after a single dose of black tea (van het Hof et al. 1998). The second blood sample for measurement of platelet aggregation and blood lipids, and the second spot urine sample for measurement of 4-O-methylgallic acid, were taken $4 \mathrm{~h}$ after the dairy fat.

A blended black tea obtained from the Tea Trade Health Research Association (Toronto, Ontario, Canada) was used. Tea leaves $(2 \mathrm{~g})$ in a spring-handled infuser were infused in $250 \mathrm{ml}$ boiled water for $1 \mathrm{~min}$ with constant movement, then consumed without milk and sugar. Most of the waterextractable antioxidants (polyphenols) in black tea can be extracted using this method within 1 min (Hodgson et al. 1999). The control drink was the same volume of boiled water consumed hot. Participants were instructed not to make any changes to their usual food intake, alcohol consumption and physical activity between the two clinic visits. Body weight and height were measured at the first visit, and body weight again at the second visit. BMI (weight $(\mathrm{kg}) /$ height $(\mathrm{m})^{2}$ ) was calculated.

Blood for platelet aggregation was processed immediately and the assessments performed using fresh platelets (see later for method). Serum total cholesterol and triacylglycerol concentrations were analysed enzymatically on a Roche Diagnostics Cobas Mira analyser (Basel, Switzerland) with the use of reagents from Trace Scientific (Perth, Australia). The urinary concentrations of 4- $O$-methylgallic acid, which have been shown to be a marker of the intake of black tea (Hodgson et al. 2000a,b), were measured using a method previously described (Hodgson et al. 2000b).

\section{Platelet aggregation}

The same technician, who was blinded to the treatment, performed all platelet aggregation assessments within $1 \mathrm{~h}$ of blood sampling. Blood $(20 \mathrm{ml})$ was collected into polypropylene tubes containing trisodium citrate $(380 \mathrm{~g} / \mathrm{l})$. Platelet-rich plasma (PRP) was prepared by centrifugation at $190 \mathrm{~g}$ for $10 \mathrm{~min}$. The PRP was removed and the blood centrifuged once more at $2000 \mathrm{~g}$ for $10 \mathrm{~min}$ to provide platelet-poor plasma. A platelet count in PRP was performed using a haemacytometer, then the PRP was diluted with platelet-poor plasma to give a platelet count of $2.5 \times 10^{8} / \mathrm{ml}$. Platelet aggregation was assessed in a model 490-4D Chronolog Aggregometer (Crono-log Corp., Havertown PA, USA) by the optical density method in response to collagen and ADP (Helena Laboratories, Beaumont, TX, USA). Aggregations were performed in $500 \mu \mathrm{l}$ aliquots of PRP added to cuvettes after equilibration at $37^{\circ} \mathrm{C}$ for $5 \mathrm{~min}$. Aggregants were added to the bottom of the cuvette with continuous mixing with a magnetic stirrer. Three concentrations of each aggregant were used: $0.2,0.6,2.0 \mu \mathrm{g}$ collagen/ml; 2, 4, $8 \mu \mathrm{M}$-ADP. Aggregation was measured as percentage light transmittance at $0.5 \mathrm{~s}$ intervals up to $5 \mathrm{~min}$ after addition of aggregant.

For statistical comparisons, areas under the aggregation curves were used. The combined data were used initially to determine whether black tea had an overall effect on postprandial collagen or ADP-induced aggregation. The combined aggregation curves for collagen and ADP were calculated as: (\% aggregation $\times$ time $(\mathrm{s}) \times$ dose $(\mu \mathrm{g} / \mathrm{ml}$ or $\mu \mathrm{M})) / 100$. This gives an aggregation curve that takes into account all three concentrations of either collagen or ADP. Individual comparisons were also made for each dose of collagen or ADP, and the curves are presented graphically as percentage aggregation over time: (\% aggregation $\times$ time(s))/100).

\section{Statistics}

All analyses were performed using SPSS 10.0 software (SPSS, Chicago, IL, USA). Results are presented as mean 
Tea and postprandial platelet aggregation
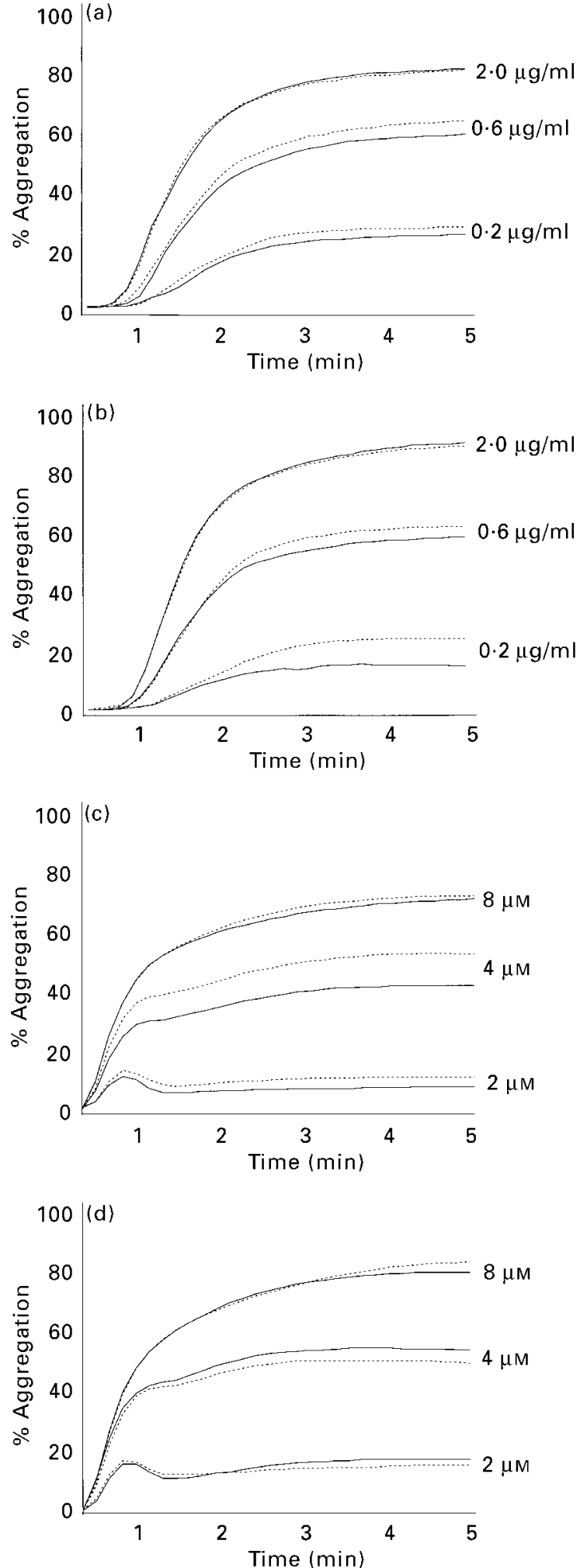

Fig. 1. Mean percent aggregation over $5 \mathrm{~min}$ at baseline (- - - -) and at $4 \mathrm{~h}(\longrightarrow)$ after $50 \mathrm{~g}$ dairy fat for collagen-induced aggregation $(a, b)$ and ADP-induced aggregation (c, d), following hot water $(a, c)$ or black tea $(b, d)$ in twenty subjects. For details of subjects and procedures, see p. 142.

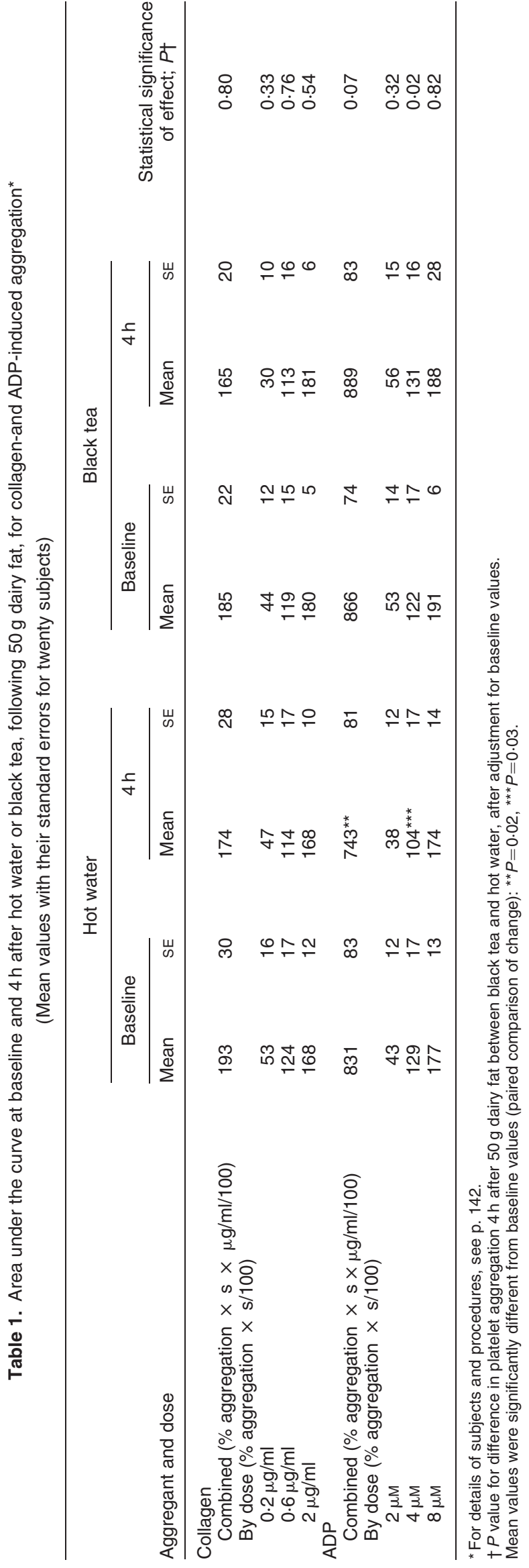


values with their standard errors and $P<0.05$ was considered significant. The area under the aggregation curves was determined using Prism statistical analysis software (Graphpad Inc., San Diego, CA, USA). Pearson's correlation coefficient $(r)$ with two-tailed $P$ value was used to determine the degree and direction of association between two variables. The paired $t$ test was used to assess the within-group change from baseline. General linear models were used to compare platelet aggregation and blood lipids between drinks at $4 \mathrm{~h}$, after adjusting for baseline values.

\section{Results}

The participants were aged between 43 and 67 years with a mean age of 58.3 (SE 1.5) years. They had a BMI 27.5 (SE 0.7 ), range $23 \cdot 5-35.7 \mathrm{~kg} / \mathrm{m}^{2}$. The mean baseline fasting total cholesterol concentration was 5.73 (SE 0.15), range $4.85-6.95 \mathrm{mmol} / \mathrm{l}$, and mean fasting triacylglycerol was $1 \cdot 11$ (SE 0.10), range $0 \cdot 65-2 \cdot 10 \mathrm{mmol} / 1$.

Serum total cholesterol and triacylglycerol concentrations increased significantly $4 \mathrm{~h}$ after ingesting the dairy fat. Following the dairy fat, serum total cholesterol concentrations increased from 5.70 (SE 0.15) to 5.82 (SE $0 \cdot 16) \mathrm{mmol} / \mathrm{l}(P=0.001)$ after drinking hot water, and from $5.76(\mathrm{SE} 0.16)$ to $5.93(\mathrm{SE} 0.17) \mathrm{mmol} / \mathrm{l}(P=0.03)$ after drinking black tea. Similarly, serum triacylglycerol concentrations increased from 1.14 (SE 0.11) to 1.79 (SE $0.20) \mathrm{mmol} / \mathrm{l}(P=0.0001)$ after drinking hot water, and from 1.07 (SE 0.10$)$ to $1.88(\mathrm{SE} 0.22) \mathrm{mmol} / \mathrm{l}(P=0.0001)$ after drinking black tea. There was no significant difference in the $4 \mathrm{~h}$ total cholesterol $(P=0.61)$ or triacylglycerol $(P=0 \cdot 24)$ concentrations between hot water and black tea. Urinary concentrations of 4-O-methylgallic acid were significantly increased $(P=0.0001)$ after drinking black tea (from 0.033 (SE 0.011) to $0.386(\mathrm{SE} 0.043) \mu \mathrm{mol} / \mathrm{l})$ in comparison with hot water (from 0.061 (SE 0.005) to 0.038 (SE 0.011) $\mu \mathrm{mol} / \mathrm{l}$ ) following the dairy fat.

Curves representing the mean percent aggregation over $5 \mathrm{~min}$ at baseline and at $4 \mathrm{~h}$ after $50 \mathrm{~g}$ dairy fat for collagen and ADP-induced aggregation are presented in Fig. 1. The mean baseline and $4 \mathrm{~h}$ area-under-the-curve for collagen and ADP-induced aggregation are presented in Table 1. There was a trend for combined collagen-induced aggregation to be reduced from baseline after drinking hot water $(P=0.05)$ and black tea $(P=0.06) 4 \mathrm{~h}$ after ingesting the dairy fat. In addition, combined ADP-induced platelet aggregation was significantly reduced from baseline after drinking hot water $(P=0.02)$ mainly due to a significant reduction in aggregation at the $4 \mu \mathrm{M}$ dose $(P=0.003)$. ADP-induced platelet aggregation was not altered from baseline after drinking black tea. However, at the $4 \mu \mathrm{M}$ dose of ADP, platelet aggregation was significantly different between black tea and hot water. Black tea in comparison with hot water did not influence collagen-induced postprandial platelet aggregation.

\section{Discussion}

The effects of black tea and polyphenols found in tea on platelet aggregation have previously been examined in vitro and in dietary intervention studies in human subjects. Results of in vitro studies have been consistent in showing that polyphenols found in tea can inhibit collagen-(Janssen et al. 1998; Kang et al. 1999) and ADP-(Pace-Asciak et al. 1995; Janssen et al. 1998; Kang et al. 1999; Neiva et al. 1999) induced platelet aggregation. However, controlled intervention studies using supplements containing polyphenols found in tea (Conquer et al. 1998; Janssen et al. 1998), or black tea (Duffy et al. 2001; Hodgson et al. 2001), have found no effects on ex vivo platelet aggregation.

The discrepancy between the results of in vitro and ex vivo studies has been suggested to relate to the nonphysiological concentrations of polyphenols used in the in vitro studies (Janssen et al. 1998). Concentrations of polyphenols required to inhibit aggregation in vitro have ranged from 10 to greater than $2000 \mu \mathrm{M}$. In controlled intervention studies (Conquer et al. 1998; Janssen et al. 1998; Duffy et al. 2001; Hodgson et al. 2001), plasma concentrations of specific polyphenols are unlikely to have exceeded about $2 \mu \mathrm{M}$, and composite polyphenol concentrations are unlikely to have exceeded about $10 \mu \mathrm{M}$.

We recently found that regular ingestion of black tea for 4 weeks does not inhibit platelet aggregation ex vivo (Hodgson et al. 2001). These findings have now been extended to show that black tea does not acutely inhibit postprandial platelet aggregation ex vivo. We note that at the $4 \mu \mathrm{M}$ concentration of ADP, platelet aggregation was significantly reduced from baseline with hot water, but was unchanged from baseline with black tea. Therefore, the significant difference in postprandial platelet aggregation with black tea in comparison with hot water may have resulted from the decrease in aggregation after drinking hot water rather than any real increase in aggregation after drinking black tea. One interpretation of these results is that black tea increases postprandial aggregability of platelets. However, as this was only observed with one of the three concentrations of ADP, it may be a chance finding. A further possible explanation is that the effect of fat to decrease aggregation, and the effect of black tea to prevent this decrease in aggregation, are in vitro phenomena that have little relevance to platelet function in vivo.

Many studies have investigated the effects of dietary fat on postprandial platelet aggregation. These studies show that dietary fat can modify platelet aggregation ex vivo during postprandial lipaemia, but observed effects have been inconsistent (Nimpf et al. 1989; Freese \& Mutanen 1995). Postprandial lipaemia has been reported to reduce, not alter or increase platelet aggregation in response to collagen or ADP. In addition, platelet aggregation responses to collagen have differed to those with ADP within studies, and have not been consistent between studies (Nimpf et al. 1989; Freese \& Mutanen, 1995). These inconsistent and often contradictory results have not been adequately explained. Several factors such as the study design, population studied and assay procedure, in particular whether or not PRP or washed platelets were used (Bisovsky et al. 1992), may have accounted for the contradictory results.

The relevance of decreases in platelet aggregation, which we and others have observed with postprandial lipaemia, to effects of postprandial lipaemia on platelet function in vivo 
remains uncertain. It is possible that this is an in vitro phenomenon as a result of using PRP (Aviram et al. 1985; Bisovsky et al. 1992) rather than diminution in the propensity of platelets to aggregate in vivo. This would mean that the observed increase in platelet aggregation with black tea in comparison with hot water could not be interpreted as an effect of black tea to increase aggregation and impair platelet function. A significant reduction in soluble P-selectin, a marker of platelet activation, with regular ingestion of black tea (Hodgson et al. 2001) is not consistent with effects of black tea to increase platelet aggregation. Furthermore, the growing evidence that hypertriacylglycerolaemia represents a procoagulant state (Miller et al. 1991; Salomaa et al. 1993; Silveira et al. 1994; Mutanen \& Freese, 2001), with increased platelet activation (Broijersen et al. 1998) is not consistent with a decrease in susceptibility of platelets to aggregate postprandially.

In conclusion, results of previous studies indicate that regular ingestion of black tea does not inhibit platelet aggregation ex vivo in the fasting state (Hodgson et al. 2001). The results of the present study indicate that black tea does not inhibit postprandial platelet aggregation ex vivo. Therefore, the present results do not support the suggestion that reduced postprandial platelet aggregability contributes to any benefits of black tea on cardiovascular risk. However, the value of measurement of platelet aggregation ex vivo in the assessment of postprandial platelet function is uncertain.

\section{Acknowledgements}

This study was supported by grants from the Tea Trade Health Research Association and the National Heart Foundation of Australia. The authors wish to thank Lyn McCahon, Penny Rogers and Susan $\mathrm{Ng}$ for their help in carrying out the study.

\section{References}

Aviram M, Furman B \& Brook JG (1985) Chylomicrons from patients with type $\mathrm{V}$ hyperlipoproteinemia inhibit platelet function. Atherosclerosis 56, 157-167.

Bisovsky S, Richter H, Fitscha P, O’Grady J \& Sinzinger H (1992) Postprandial hyperlipemia does not inhibit platelet aggregation. Prostaglandins Leukotrienes and Essential Fatty Acids 47, 331-332.

Broijersen A, Karpe F, Hamsten A, Goodall AH \& Hjemdahl P (1998) Alimentary lipemia enhances the membrane expression of platelet P-selectin without affecting other markers of platelet activation. Atherosclerosis 137, 107-113.

Conquer JA, Maiani G, Azzini E, Raguzzini A \& Holub BJ (1998) Supplementation with quercetin markedly increases plasma quercetin concentration without effect on selected risk factors for heart disease in healthy subjects. Journal of Nutrition 128, $593-597$.

Duffy SJ, Vita JA, Holbrook M, Swerdloff PL \& Keaney JF Jr (2001) Effect of acute and chronic tea consumption on platelet aggregation in patients with coronary artery disease. Arteriosclerosis Thrombosis and Vascular Biology 21, 1084-1089.

Formica JV \& Regelson W (1995) Review of the biology of quercetin and related bioflavonoids. Food and Chemical Toxicology 33, 1061-1080.

Freese R \& Mutanen M (1995) Postprandial changes in platelet function and coagulation factors after high-fat meals with different fatty acid compositions. European Journal of Clinical Nutrition 49, 658-664.

Hertog MG, Feskens EJ, Hollman PC, Katan MB \& Kromhout D (1993) Dietary antioxidant flavonoids and risk of coronary heart disease. Lancet 342, 1007-1011.

Hertog MGL \& Hollman PCH (1996) Potential health effects of the dietary flavonol quercetin. European Journal of Clinical Nutrition 50, 63-71.

Hodgson JM, Morton LW, Puddey IB, Beilin LJ \& Croft KD (2000a) Gallic acid metabolites are markers of black tea intake in humans. Journal of Agricultural and Food Chemistry 48, 2276-2280.

Hodgson JM, Proudfoot JM, Croft KD, Puddey IB, Mori TA \& Beilin LJ (1999) Comparison of the effects of black and green tea on in vitro lipoprotein oxidation in human serum. Journal of the Science of Food and Agriculture 79, 561-566.

Hodgson JM, Puddey IB, Croft KD, Burke V, Mori TA, AbuAmsha Caccetta R \& Beilin LJ (2000b) Acute effects of ingestion of black and green tea on lipoprotein oxidation. American Journal of Clinical Nutrition 71, 1103-1107.

Hodgson JM, Puddey IB, Mori TA, Burke V, Baker R \& Beilin LJ (2001) Effects of regular ingestion of black tea on haemostasis and cell adhesion molecules in humans. European Journal of Clinical Nutrition 55, 881-886.

Janssen K, Mensink RP, Cox FJ, Harryvan JL, Hovenier R, Hollman PC \& Katan MB (1998) Effects of the flavonoids quercetin and apigenin on hemostasis in healthy volunteers: results from an in vitro and a dietary supplement study. American Journal of Clinical Nutrition 67, 255-262.

Kang WS, Lim IH, Yuk DY, Chung KH, Park JB, Yoo HS \& Yun YP (1999) Antithrombotic activities of green tea catechins and (-)-epigallocatechin gallate. Thrombosis Research 96, 229-237.

Keli SO, Hertog MGL, Feskens EJM \& Kromhout D (1996) Dietary flavonoids, antioxidant vitamins, and incidence of stroke. Archives of Internal Medicine 156, 637-642.

Miller GJ, Martin JC, Mitropoulos KA, Reeves BE, Thompson RL, Meade TW, Cooper JA \& Cruickshank JK (1991) Plasma factor VII is activated by postprandial triglyceridemia, irrespective of dietary fat composition. Atherosclerosis 86, 163-171.

Mutanen M \& Freese R (2001) Fats, lipids and blood coagulation. Current Opinion in Lipidology 12, 25-29.

Neiva TJC, Morais L, Polack M, Simoes CMO \& D'Amico EA (1999) Effects of catechins on human blood platelet aggregation and lipid peroxidation. Phytotherapy Research 13, 597-600.

Nimpf J, Malle E, Leopold B, Wurm H \& Kostner GM (1989) Postprandial hyperlipemia inhibits platelet aggregation without affecting prostanoid metabolism. Prostaglandins Leukotrienes and Essential Fatty Acids 37, 7-13.

Pace-Asciak CR, Hahn S, Diamandis EP, Soleas G \& Goldberg DM (1995) The red wine phenolics trans-resveratrol and quercetin block human platelet aggregation and eicosanoid synthesis: implications for protection against coronary heart disease. Clinica Chimica Acta 235, 207-219.

Salomaa V, Rasi V, Pekkanen J, Jauhiainen M, Vahtera E, Pietinen P, Korhonen H, Kuulasmaa K \& Ehnholm C (1993) The effects of saturated fat and $n-6$ polyunsaturated fat on postprandial lipemia and hemostatic activity. Atherosclerosis 103, 1-11.

Silveira A, Karpe F, Blomback M, Steiner G, Walldius G \& Hamsten A (1994) Activation of coagulation factor VII during alimentary lipemia. Arteriosclerosis and Thrombosis 14, 60-69. van het Hof KH, Kivits GA, Weststrate JA \& Tijburg LB (1998) Bioavailability of catechins from tea: the effect of milk. European Journal of Clinical Nutrition 52, 356-359. 